\title{
Pelatihan Jurnalistik Untuk Siswa Kelas XI MA Darussalam Barambai
}

\author{
M. Ridha Anwari*, Muhammad Yunus \\ Program Studi Pendidikan Bahasa Indonesia Fakultas Keguruan dan Ilmu Pendidikan \\ Universitas Muhammdiyah Banjarmasin \\ e-mail: ridhaanwari90@gmail.com
}

\begin{abstract}
This service aims to improve students' mental and academic abilities in understanding and practicing journalistic issues, especially writing news articles. The method used in this service is in the form of lectures, discussions, questions and answers, simulations of writing news articles, and evaluating. The target in this service is class XI students in MA Darussalam Barambai consisting of only 1 class. The results of this community service show that class XI students in MA Darussalam Barambai get good grades in the simulation of making articles / news manuscripts. $80 \%$ have reached the completeness criteria and passed. $20 \%$ is still in the realm of space and needs more practice in writing article scripts.
\end{abstract}

Keywords: Training, Journalism, Madrasah Aliyah, Barambai

\section{Abstrak}

Pengabdian ini bertujuan untuk meningkatkan mental dan kemampuan akademis siswa dalam memahami dan mempraktekkan masalah jurnalistik terutama penulisan artikel berita. Metode yang digunakan dalam pengabdian ini adalah berbentuk ceramah, diskusi, tanya jawab, simulasi penulisan naskah artikel berita, serta evaluasi. Sasaran dalam pengabdian ini adalah siswa kelas XI di MA Darussalam Barambai yang terdiri dari 1 kelas saja. Hasil dari kegiatan pengabdian ini menunjukkan bahwa siswa kelas XI di MA Darussalam Barambai mendapatkan nilai yang baik dalam simulasi pembuatan naskah artikel/berita. $80 \%$ telah mencapai kriteria ketuntasan dan lulus. $20 \%$ masih berada dalam ranah cukup dan perlu lebih banyak latihan lagi dalam menulis naskah artikel.

Kata Kunci : Pelatihan, Jurnalistik, Madrasah Aliyah, Barambai

\section{PENDAHULUAN}

Bagi para penulis dan jurnalis (wartawan), bahasa adalah senjata, dan kata-kata adalah pelurunya. Mereka tidak mungkin bisa memengaruhi pikiran, suasana hati, dan gejolak pe-rasaan pembaca, pendengar, atau pemirsanya, jika tidak menguasai bahasa jurnalistik dengan baik dan benar. Itulah sebabnya, para penulis dan jurnalis harus dibekali penguasaan yang memadai atas kosa kata, pilihan kata, kalimat, paragraf, gaya bahasa, dan etika bahasa jurnalistik.

Bahasa jurnalistik harus memenuhi sejumlah persyaratan, seperti tampil menarik, variatif, segar, berkarakter. Selain itu, ia juga harus senantiasa tampil ringkas dan lugas, logis, dinamis, demokratis, dan populis. Dalam bahasa jurnalistik, setiap kata harus bermakna, bahkan harus bertenaga, dan bercita rasa. Kata bertenaga dengan cepat dapat membangkitkan daya motivasi, persuasi, fantasi, dan daya imajinasi pada benak khalayak.

Penulisan berita di media massa menggunakan bahasa jurnalistik yang disyaratkan tampil menarik, variatif, segar, berkarakter. Selain itu, ia juga harus senantiasa tampil ringkas dan lugas, logis, dinamis, demokratis. Dalam bahasa jurnalistik, setiap kata harus bermakna, bertenaga, dan bercita rasa. Kebanyakan penulisan berita di media massa tersebut sering terdapat penyimpanganpenyimpangan dari kaidah penullisan tata bahasa yang benar. Karena alasan menarik, variatif, segar, berkarakter itulah yang menyebabkan penulisan berita dimedia 
massa tidak sesuai dengan kaidah penulisan tata bahasa yang benar.

Dalam masyarakat ada sebagian pihak yang bertanya apakah memang ada bahasa jurnalistik itu? Untuk apa bahasa jurnalistik? Biasanya, mereka yang bertanya seperti itu tergolong yang punya kepedulian terhadap seluk beluk berbahasa Indonesia yang baik dan benar. Selebihnya, masyarakat pada umumnya mengabaikan perbedaan antara bahasa jurnalistik dengan bahasa pasar yang digunakan dalam kehidupan sehari-hari.

Manusia pada era konvergensi media massa ini, tidak mungkin melakukan pengembangan diri dan masyarakat tanpa mengakses berita, fakta, ilustrasi, gagasan, dan informasi dari berbagai media komunikasi massa baik secara tradisional maupun media massa kontemporer (Santana K., 2005: 152).

Bermula dari abad ke-19 setelah manusia melakukan revolusi industri, mereka menyempurnakan berbagai teknologi untuk membantu kehidupan mereka. Antara pabrik dengan pertanian pun disambungkan. Manusia tidak lagi hanya melakukan komunikasi antarpribadi dan kelompok. Teknologi komunikasi mempertemukan manusia melalui industri telepon, surat kabar, majalah, fotografi, radio, film, televisi, komputer dan satelit serta internet. Manusia kini berada dalam abad informasi.

Bagaimana media massa mentransmisikan informasi dan edukasi? Bagaimana media massa menjalankan fungsinya sebagai pelaku kontrol sosial, pewaris nilai kebudayaan, penafsir berita dan penyedia hiburan? Bahkan Marshall McLuhan mengkosmologikan era global village, kampung global. Media membuat jutaan orang bisa "melihat dunia" secara langsung dan serentak.

Semua itu ditumbuhkan oleh para pekerja media. Pekerjaan mereka, yang kian jadi profesi, menciptakan pesan yang kian efektif. Dari suara elektronis yang semakin human, sampai halaman cetak dan huruf-huruf billboard elektronis, semuanya mengakumulasi. Ini hasil trial and error pekerja dan akdemisi ketika mengembangkan proses komunikasi massa. Mereka meneliti unsur-unsur pesan, individu pengirim, khalayak dan berbagai efek komunikasi massa.

Pekerja media menata pesan massal dengan memanfaatkan ruang dan waktu teknologi media. Suara-suara elektronis "human" memproses terpaan sampai ke bunyi mendesis dalam satuan waktu siaran. Kata-kata cetak disusun hingga mengajak keaktifan masyarakat ke ruang-ruang imaji sosial. Sistematika pesan dikalkulasi sampai ke rincian efek "titik dan koma", bukan hanya semata-mata gramatika bahasa. Pesan ditata supaya memiliki daya pikat selera massa di berbagai ruang pengalaman dan referensi sosial.

Pers (baca: pekerja media) menjadi sebuah proses mediasi antara masyarakat dengan "dunia". Pers diproses oleh jurnalisme untuk memiliki daya persuasi. Jurnalisme memrosesnya melalui tata cara mencari dan menyebarkan informasi. Jurnalisme selalu mengembangkan teknik prliputan dan pendistribusian pesan yang sesuai dengan kultur masyarakat. Pada proses pengembangannya, perancangan informasi mendorong kelahiran fenomena bahasa pers.

Bahasa pers menjadi satu alat. Bahasa, di dalam kehidupan jurnalistik, tidak lagi sekadar sarana penghantar pesan melainkan menjadi daya dorong lain. Dalam perkembangannya, memengaruhi kegiatan pers sampai ke tingkat pengepingan realitas peristiwa berita. Tata nilai dan norma bahasa jurnalistik menjadi kelembagaan bahasa yang unik, dan bila dipolakan, menginduksi wacana masyarakat ketika menempatkan perspektif atas realitas.

Bahasa jurnalistik sebagai salah satu variasi Bahasa Indonesia tampak jelas kegunaanya bagi masyarakat yang mendengarkan informasi dari radio setiap hari, membaca berita koran, tabloid dan majalah setiap jam, menyaksikan tayangan televisi yang melaporkan berbagai 
ISSN : 2550-0198

peristiwa yang terjadi di berbagai belahan bumi. Semua berita dan laporan itu disajikan dalam bahasa yang mudah dipahami oleh khalayak, mereka seolaholah diajak untuk menyaksikan berbagai peristiwa secara langsung. Dengan demikian bahasa jurnalistik itu menjadi bagian tak terpisahkan dalam karya jurnalistik.

Madrasah Aliyah Barambai yang terletak di Kabupaten Barito Kuala ini tergolong sebagai sekolah terpinggirkan karena jaraknya yang jauh dari perkotaan, minimnya fasilitas, dan kurangnya sarana yang menunjang pembelajaran. Hal ini juga berpengaruh pada aspek-aspek keterampilan yang dikuasai siswa termasuk keahlian dalam jurnalistik.

Permasalahan yang dialami mitra yaitu kurangnya wawasan dan keterampilan mengenai jurnalistik. Baik dalam penulisan berita, artikel, dan lain sebagainya. Oleh karena itu perlu adanya solusi untuk memecahkan permasalahan ini yaitu dengan mengadakan pelatihan terkait jurnalistik agar siswa mempunyai keterampilan yang baik dalam penulisan, khusunya bidang jurnalistik.

\section{METODE PENGABDIAN}

Pelaksaan pengabdian masyarakat ini dilaksanakan selama bulan Januari 2020, bertempat di MA Darussalam Barambai. Sasaran dalam pengabdian ini adalah siswa kelas XI MA Darussalam Barambai.

Kegiatan ini dilaksanakan dalam bentuk ceramah/diskusi dan simulasi penulisan artikel maupun berita. Aktivitas pengabdian ini disjaikan dalam bentuk tabel.

Tabel 1. Tahapan Pelaksanaan Kegiatan

\begin{tabular}{|c|c|c|c|c|}
\hline No & Hari/tanggal & Kegiatan & Metode & Keterangan \\
\hline 1 & $\begin{array}{l}\text { Jumat, } 3 \\
\text { Januari } 2020\end{array}$ & $\begin{array}{l}\text { Mengurus surat } \\
\text { izin pengabdian } \\
\text { dan surat tugas } \\
\text { dari LP2M }\end{array}$ & & $\begin{array}{l}\text { Surat selesai } \\
\text { dalam waktu } 2 \\
\text { hari }\end{array}$ \\
\hline 2 & $\begin{array}{l}\text { Senin, } 5 \text { Januari } \\
2020\end{array}$ & $\begin{array}{l}\text { Tim Pengabdian } \\
\text { mengantar surat } \\
\text { izin ke MA } \\
\text { Darussalam } \\
\text { Barambai }\end{array}$ & & $\begin{array}{l}\text { Sekolah } \\
\text { menyambut baik } \\
\text { kegiatan } \\
\text { pengabdian }\end{array}$ \\
\hline 3 & $\begin{array}{l}\text { Rabu-Kamis, 7- } \\
8 \text { Januari } 2020\end{array}$ & $\begin{array}{l}\text { Tim melakukan } \\
\text { pengabdian }\end{array}$ & $\begin{array}{l}\text { Ceramah } \\
\text { Diskusi } \\
\text { Simulasi }\end{array}$ & $\begin{array}{l}\text {-Menjelaskan } \\
\text { materi jurnalistik } \\
\text {-Mendiskusikan } \\
\text {-Simulasi } \\
\text { Penulisan }\end{array}$ \\
\hline 4 & $\begin{array}{l}\text { Jumat, } 9 \\
\text { Januari } 2020\end{array}$ & Evalusai & & \\
\hline 5 & $\begin{array}{l}\text { Senin-Selasa, } \\
\text { 13-14 Januari } \\
2020\end{array}$ & $\begin{array}{l}\text { Menyusun } \\
\text { Laporan terkait } \\
\text { Artikel Buatan } \\
\text { Siswa }\end{array}$ & & $\begin{array}{l}\text { Mengumpulkan } \\
\text { berkas dan } \\
\text { dokumentasi } \\
\text { pengabdian }\end{array}$ \\
\hline
\end{tabular}

\section{HASIL DAN PEMBAHASAN}

Hasil yang dicapai dalam kegiatan pengbdian ini adalah $80 \%$ siswa mampu menulis artikel berita dengan baik. Pelatihan ini sangat bermanfaat bagi para siswa kelas XI Darussalam Barambai yang telah mulai mampu membuat artikel berita dan menentukan tema yang bisa diangkat dalam artikel. Namun, hasil ini belum maksimal karena masih ada siswa yang belum mencapai ketuntasan sebanyak $20 \%$. Oleh karena itu perlu dilakukan pengabdian selanjutnya yang berkesinambungan agar tujuan sekolah untuk meluluskan semua siswanya bisa tercapai.

Dari hasil kegiatan pengabdian pelatihan penguasaan menuis artikel berita bahasa Indonesia menunjukkan bahwa $80 \%$ siswa memahami dan memperoleh hasil yang baik dalam pelatihan penulisan jurnalistik, terutama pembuatan artikel berita. Hasil ini menggambarkan bahwa para siswa memperoleh kategori yang baik dan sebagian masih perlu bimbingan lanjutan. Berikut beberapa foto pendampingan pengabdian di MA Darussalam Barambai.

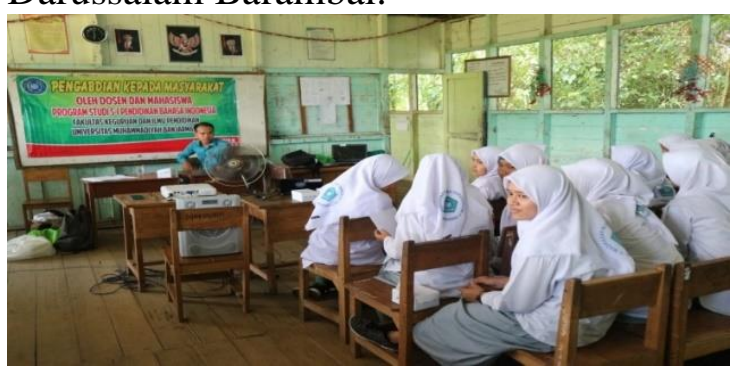

Gambar 1 Pemberian Materi 


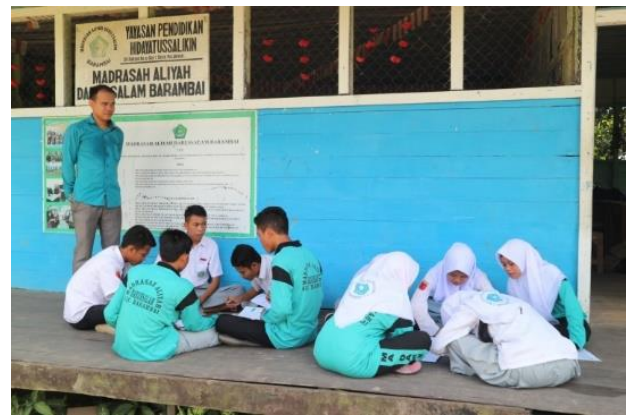

Gambar 2 Simulasi Penulisan Artikel

\section{SIMPULAN}

Kegiatan pengabdian ini dalam bentuk pembahasan materi-materi jurnalistik dan berbentuk simulasi pembuatan naskah berita. Kegiatan ini mampu meningkatkan pemahaman siswa dalam memecahkan materi-materi terkait, serta mencapai hasil yang baik yaitu $80 \%$ siswa mampu menulis artikel berita.

\section{UCAPAN TERIMA KASIH}

Ucapan terima kasih disampaikan kepada

1. Kepala MA Darussalam Barambai yang telah memfasilitasi kegiatan ini.

2. Seluruh siswa peserta pelatihan kegiatan.

\section{DAFTAR PUSTAKA}

[1] Aksin, Nur. 2016. "Peran Medsos Terhadap Pemanfaatan Media Sosial" dalam Jurnal Informatika UPGRIS, Vol. 2 No. 2 (Desember 2016).

[2] Alwi, Hasan . 2003. Tata Bahasa Baku Bahasa Indonesia. Jakarta.

[3] Badudu, J.S. (1988). Cakrawala Bahasa Indonesia. Jakarta: Gramedia.

[4] Fadjrani Sulistyo. 2004. Organisasi Profesi Jurnalis dan Kode Etik. Jurnalistik. Vol 1. No. 1, (Juni 2019).

[5] Hamna, Dian Muhtadiah. 2017. "Eksistensi Jurnalisme di Era Media Sosial" dalam Juurnalisa. Vol 3 No 1. (Mei 2017).]

[6] Lembaga Pers Dr. Soetomo. 2009. Kesalahan bahasa jurnalistik perparah kerusakan bahasa. Jakarta.
[7] Nuraeni, Reni. 2017. "Peran Medsos dalam Tugas Jurnalistik” dalam Jurnal Ilmiah LISKI (LingkarStudi Komunikasi), Vol 3 No 1 (Juni 2017).

[8] Tubiyono. 2011. "Bahasa Indonesia Jurnalistik", (online), (http://www.tubiyono.com/, diakses, 2 April 2019)

[9] Wahid, Abdul. 2011. "Penyimpangan Bahasa Jurnalistik", (online), (http://www.pa- magelang.go.id/, diakses, 1 April 2019) 